\title{
AMA Journal of Ethics
}

\section{April 2015, Volume 17, Number 4: 375-380}

\section{SECOND THOUGHTS}

\section{Complementary and Alternative Treatments for Autism Part 2: Identifying and Avoiding Non-Evidence-Based Treatments \\ Alison Singer, MBA, and Ramita Ravi}

Editor's note: This is the second of a two-part series. Read Part 1.

The pace and progress of autism research has increased dramatically over the past five years. Yet, despite these advancements, we have not yet identified a singular cause of or cure for autism. Consequently, some parents fall victim to the allure of unproven complementary and alternative medicine, known as CAM, as potential remedies for their children's symptoms.

Although a wide spectrum of therapeutic practices exists, there are four major domains of CAM autism treatments: mind-body medicine interventions (intended to target interactions between brain and behavior), biology-based treatments (proffering natural substances as treatment alternatives), manipulative and body-based practices (that attempt to treat conditions through body manipulation), and energy medicine ("channeling energy" to promote healing). Common CAM techniques for treating autism include dietary supplements, vitamins, hyperbaric oxygen, hormone injections, swimming with dolphins, horseback riding, yoga, and massage. While these remedies may seem enticing and low-risk, there is not enough evidence to suggest that they effectively reduce symptoms of autism. Furthermore, some of these non-evidencebased treatments can be downright dangerous.

Studies show that 50-75 percent of children with autism use some CAM in an effort to improve symptoms [1, 2]. Approximately half of these children use biology-based therapies, 30 percent use mind-body therapies, and 25 percent use manipulation or body-based therapies [2]. In our opinion, most families try CAM because they hear about it in the media, perceive it as "natural," and are eager to leave no stones unturned in their efforts to manage autism symptoms. Very few studies have proven the efficacy of these kinds of CAM in alleviating symptoms of autism. Doctors must direct parents away from non-evidence-based practices that may be detrimental to children's health.

Many CAM practices are based on misguided theories about the causes of autism. The rationale for diets free of gluten (protein found in wheat, rye, and barley) and casein (protein found in dairy products), for example, is the claim that children with autism have "leaky guts" that allow opioids from these proteins to enter the bloodstream, travel into 
the brain, and cause autistic behaviors [3]. Yet, research has consistently demonstrated no difference between bloodstream opioid levels in individuals with autism and in neurotypical individuals $[4,5]$. What has been proven by research is that a gluten- and casein-free diet is related to lower bone density, which can lead to osteoporosis [6]. Studies testing the efficacy of a gluten-free and casein-free diet in treating autism using randomized, double-blind, repeated measure crossover designs have yielded no statistically significant findings, even though several parents reported improvement in their children $[7,8]$.

Chelation therapy is another CAM practice that is based on an unproven notion of what causes autism. During chelation therapy, chemicals are administered that bind to heavy metals, such as mercury, and eliminate them from the body. However, there is no evidence that autism is caused by heavy metal poisoning, nor are there any controlled studies that show this practice to be safe or effective. In fact, in 2005 a child died when a chelating agent bonded with calcium and caused the child's heart to stop [9].

Lupron therapy is also offered in a misguided attempt to cure what doesn't actually cause autism. Lupron is a testosterone-inhibiting drug used to treat prostate cancer and precocious puberty. Use of Lupron in children with autism is based on the notion that testosterone magnifies the effect of mercury and that reducing testosterone would reduce the effects of mercury [10]. There are no studies indicating mercury causes autism or that mercury bonds to testosterone. Lupron also has many harmful side effects including numbness, weakness, difficulty breathing, trouble swallowing, hives, blood in the urine, bone pain, testicular pain, and osteoporosis [11].

It is important to note that risky CAM treatments are not limited to drugs. Holding therapy, for example, is a manipulative, body-based therapy that stems from the erroneous notion that autism is caused by a parent's failure to bond with his or her child [12]. In a holding therapy session, caregivers physically restrain children and force eye contact, hoping to repair the emotional detachment [13]. Because of the intense physical pressure applied by caregivers, this practice is risky and has even led to fatalities [14]. This treatment is dangerous, there is no evidence to support its efficacy, and it is founded upon a hypothesis inconsistent with medical models [13].

\section{Identifying an Unsupported CAM Treatment}

Unfortunately, there are many unscrupulous charlatans who are eager to take advantage of parents desperate to try anything that sounds like it might help their children with autism. We receive several emails a week from practitioners offering "the cure" for autism (often for the "low, low price" of \$299). We are often horrified at how these emails use guilt and guile to encourage families to try these untested treatments because "if you really loved your child, wouldn't you want to leave no stone unturned?" 
At the Autism Science Foundation, we urge parents to be particularly wary of untested treatments and of practitioners who are unwilling to submit their treatments to the rigor of a double-blind, randomized, placebo-controlled trial. Many practitioners of these supposed cures will say things like "I know it works," "I've seen it work," or "I don't want to spend time and money testing it when it could be helping children right away." We urge parents to run, not walk, away from any treatment that claims to be too good for science.

When studies of a treatment are published, both physicians and parents need to look carefully to be sure that they are published in a reputable peer-reviewed scientific journal. Not all journals are created equal; the Internet has made it possible for anyone to publish a "journal," and paid search optimization has made it easy for anyone to make their study appear first in a Google search. But a journal published online by the scientist in her basement that is "peer-reviewed" by her cousin is not the same as a study published in a high-impact, reputable medical journal edited and peer-reviewed by proven leaders in the field.

Even studies published in reliable journals should be questioned. A treatment that is truly effective will be backed up with clear evidence and proper methodology. In intervention studies, appropriate methodology includes the use of well-matched control groups, preand post-treatment testing, representative samples, sufficient sample sizes, random assignment, and procedures to eliminate bias. In intervention testing for autism, control groups should be matched according to sex, age, diagnosis, and functionality. Additionally, in order to eliminate bias, both investigators and participants should be "blinded" and remain unaware of whether a participant is receiving a placebo or treatment.

Publications of research that demonstrate positive results for a treatment are often unlikely to highlight any methodological flaws in the studies. That's why parents and doctors should review methodology and look carefully at study design and execution. For example, vitamin B6 and magnesium dietary supplements have been a popular treatment for autism for the past 20 years [6]. Three controlled studies published between 1993 and 2002 claimed that B6 and magnesium were effective treatments for autism. However, in a recent literature review, Susan E. Levy, MD, of Children's Hospital of Philadelphia and Susan Hyman, MD, of University of Rochester Medical Center pointed out that all three studies had inadequately described the diagnosis of autism and had failed to establish proper "selection criteria and outcome measures" [6]. They concluded that, because of the small number of studies and their improper methodology and small sample sizes, there was not adequate evidence to support the use of these treatments.

Parents and physicians also need to read studies carefully to determine whether the study provides evidence that a particular treatment alleviates symptoms specific to 
autism. For example, studies show that yoga, a mind-body CAM practice, reduces anxiety [15]. But there is no evidence and no reason to believe that yoga affects individuals with autism who are not also diagnosed with anxiety any differently than it affects children with other types of disabilities or with no disabilities. Yet, practitioners tout yoga as a treatment for autism [16].

\section{Conclusion}

While many CAM practices sound harmless enough, many are dangerous as well as ineffective. Parents want to do everything they can to help their children with autism, but unstudied and ineffective CAM practices are simply not worth the high risk or cost.

Fortunately, we do have good evidence-based treatments that have been proven to mitigate symptoms of autism, including applied behavior analysis, speech therapy, occupational therapy, and physical therapy. There are currently two medications approved by the US Food and Drug Administration (FDA) for symptoms associated with autism [17], and FDA-approved human clinical trials are testing medications that target the core symptoms of autism, including social and learning disabilities and language development [18]. Reliable treatments should affect specific symptoms of autism while minimizing risk to the individual. All treatments should be subjected to the rigor of welldesigned, double-blind, placebo-controlled clinical trials.

Most parents are not trained scientists. It is largely up to physicians to steer parents away from these risky, ineffective, untested practices. It is the physician's responsibility to encourage families to seek safe, effective, evidence-based interventions.

\section{References}

1. Wong HH, Smith RG. Patterns of complementary and alternative medical therapy use in children diagnosed with autism spectrum disorders. J Autism Dev Disord. 2006;36(7):901-909.

2. Hanson $E$, Kalish LA, Bunce $E$, et al. Use of complementary and alternative medicine among children diagnosed with autism spectrum disorder. J Autism Dev Disord. 2007;37(4):628-636.

3. GFCF Diet. The GFCF diet intervention - autism diet: frequently asked questions. http://www.gfcfdiet.com/TheBigFAQ'S.htm. Accessed February 9, 2015.

4. Hunter LC, O'Hare A, Herron WJ, Fisher LA, Jones GE. Opioid peptides and dipeptidyl peptidase in autism. Dev Med Child Neurol. 2003;45(2):121-128.

5. Cass $\mathrm{H}$, Gringras $\mathrm{P}$, March J, et al. Absence of urinary opioid peptides in children with autism. Arch Dis Child. 2008;93(9):745-750.

6. Levy SE, Hyman SL. Complementary and alternative medicine treatments for children with autism spectrum disorders. Child Adolesc Psychiatr Clin N Am. 2008; 17(4):807. 
7. Elder JH, Shankar M, Shuster J, Theriaque D, Burns S, Sherrill L. The gluten-free, casein-free diet in autism: results of a preliminary double blind clinical trial. J Autism Dev Disord. 2006;36(3):413-420.

8. Pennesi CM, Klein LC. Effectiveness of the gluten-free, casein-free diet for children diagnosed with autism spectrum disorder: based on parental report. Nutr Neurosci. 2012;15(2):85-91.

9. Kane K. Death of 5-year-old boy linked to controversial chelation therapy. Pittsburgh Post-Gazette. January 6, 2006. http://old.postgazette.com/pg/06006/633541.stm. Accessed July 9, 2014.

10. Tsouderos T. "Miracle drug" called junk science. Chicago Tribune. May 21, 2009. http://articles.chicagotribune.com/2009-05-21/news/chi-autism-lupronmay21_1_autism-one-conference-autistic-children-lupron-protocol. Accessed February 14, 2015.

11. Cunha JP. Leuprolide-injection, Lupron (cont.). MedicineNet.com. http://www.medicinenet.com/leuprolide-injection/page2.htm\#SideEffects. Accessed February 14, 2015.

12. Kanner L. Autistic disturbances of affective contact. Acta Paedopsychiatr. 1968;35(4):100-136. Reprinted from: Kanner L. Autistic disturbances of affective contact. Nerv Child. 1943;2:217-250.

13. Speltz ML. Description, history, and critique of corrective attachment therapy. The APSAC Advisor. 2002;14(3):4-8.

14. Crowder C, Lowe P. Her name was Candace. Denver Rocky Mountain News. October 29, 2000:1A, 1M-7M, 9M-12M.

15. Jensen PS, Kenny DT. The effects of yoga on the attention and behavior of boys with attention-deficit/ hyperactivity disorder (ADHD). J Atten Disord. 2004; 7(4):205-216.

16. YogAutism website. http://www.yogautism.org. Accessed February 14, 2015.

17. Warren Z, Veenstra-VanderWeele J, Stone W, et al. Therapies for Children With Autism Spectrum Disorders. Rockville, MD: Agency for Healthcare Research and Quality; 2011. Comparative Effectiveness Review 26. http://www.effectivehealthcare.ahrq.gov/ehc/products/106/656/CER26_Autis m_Report_04-14-2011.pdf. Accessed February 25, 2015.

18. Icahn School of Medicine at Mount Sinai. Seaver Autism Center: current studies. http://icahn.mssm.edu/research/centers/seaver-autismcenter/research/current-studies. Accessed February 25, 2015.

Alison Singer, MBA, is co-founder and president of the Autism Science Foundation in New York City and serves as a public member of the federal Interagency Autism Coordinating Committee (IACC), which writes the annual strategic plan to direct federal spending for autism research. She has a 17-year-old daughter with autism and an older brother with autism. She is a graduate of Yale College and Harvard Business School. 
Ramita Ravi is an undergraduate at the University of Pennsylvania in Philadelphia where she is majoring in health and societies with a concentration in public health.

\section{Related in the AMA Journal of Ethics}

Complementary and Alternative Treatments for Autism Part 1: Evidence-Supported

Treatments, April 2015

Resisting the Understandable Appeal of CAM, June 2011

The viewpoints expressed in this article are those of the author(s) and do not necessarily reflect the views and policies of the AMA.

\section{Copyright 2015 American Medical Association. All rights reserved.}

ISSN 2376-6980 